\title{
Biologia reprodutiva de Jacquinia armillaris (Primulaceae): uma espécie endêmica das restingas Brasileiras
}

\section{Reproductive biology of Jacquinia armillaris (Primulaceae):} an endemic species of the Brazilian restinga

\author{
Mariana Andrich ${ }^{1}$, Márcio Lacerda Lopes Martins ${ }^{1}$, Luciana Dias de Thomaz ${ }^{2}$, Letícia da Silva Brito ${ }^{3}$ \& \\ Rodrigo Lemes Martins ${ }^{3,4}$
}

\begin{abstract}
Resumo
Jacquinia armillaris é uma espécie que ocorre no litoral nordeste e sudeste do Brasil em formações sujeitas a intenso processo de fragmentação. Para melhor entendimento da ecologia de J. armillaris em seu habitat natural esse trabalho avaliou a biologia reprodutiva dessa espécie na restinga do Parque Estadual Paulo César Vinha, Espírito Santo, Brasil. Por meio da descrição de eventos relacionados à floração, morfologia das flores, receptividade estigmática, sistema de reprodução, viabilidade polínica e comportamento dos visitantes florais, observou-se que Jacquinia armillaris apresenta características da síndrome de cantarofilia e visitação de dois grupos de Coleoptera: Carpophilus sp. (Nitidulidae) e Horistonotus sp. (Elateridae). Os dados também sugerem que a espécie é autocompatível, porém os testes de cruzamento revelam que a espécie depende da polinização promovida pelos visitantes florais. A espécie não apresentou agamospermia e crescimento clonal, o que somado a uma baixa produção de pólen viável, a síndrome de cantarofilia e outros rigores comuns em ambientes de restinga pode resultar em anos com baixa produção de frutos.
\end{abstract}

Palavras-chave: Jacquinia, cantarofilia, biologia reprodutiva, restinga.

\begin{abstract}
Jacquinia armillaris occurs in the coastal zone of Northeast and Southeast Brazil in greatly reworked estuarine landscapes. For a better understanding of the ecology of J. armillaris in its natural habitat, this study assessed the reproductive biology of this species in the restinga of Parque Estadual Paulo César Vinha, Espírito Santo, Brazil. According to the data on flowering, floral morphology, stigmatic receptivity, reproductive system, pollen viability, and behavior of floral visitors, Jacquinia armillaris showed characteristics of cantarophily syndrome and is visited by two Coleopteras: Carpophilus sp. (Nitidulidae) and Horistonotus sp. (Elateridae). The data suggest that the species is self-compatible. However, J. armillaris depends on pollination promoted by floral visitors. Absence of agamospermy and clonal growth, plus low viable production of pollen, cantharophily and common restinga rigor are discussed as responsible factors for low fruit set, consequently producing stochastic variation in seed recruitment.
\end{abstract}

Key words: Jacquinia, cantarophily, reproductive biology, Brazilian sandy coastal plain.

\section{Introdução}

Jacquinia L. (1756) é um gênero Neotropical, com cerca de 90 espécies, recentemente relacionada na família Primulaceae (Ståhl 2010; APG 2009; Källersjö \& Ståhl 2003). Dentre as espécies desse gênero destaca-se Jacquinia armillaris Jacq., uma espécie restrita à vegetação pós-praia de restinga que ocorre no litoral Norte e Sudeste do Brasil e que, por seu porte arbustivo ou arbóreo (até seis metros de altura), se destaca nessa vegetação predominantemente reptante (Fabris et al. 1990; Garcia 1999). Conforme Weinberg (1984) esta

\footnotetext{
${ }^{1}$ Universidade Federal do Espírito Santo (UFES), Herbário VIES, Depto. Ciências Biológicas/CCHN, Av. Fernando Ferrari 514, 29075-900, Goiabeiras, Vitória, ES, Brasil.

${ }^{2}$ Universidade Federal do Recôncavo da Bahia, Centro de Ciências Agrárias, Ambientais e Biológicas, Rua Ruy Barbosa 710, 44380-000, Centro, Cruz das Almas, BA, Brasil.

${ }^{3}$ Universidade Federal do Rio de Janeiro, NUPEM, Av. São José do Barreto 764, 27965-045, São José do Barreto, Macaé, RJ, Brasil.

${ }^{4}$ Autor para correspondência: rodr.lemes@gmail.com
} 
espécie é conhecida popularmente como barbasco, pimenteira, tingüi ou capororoca, e apresenta grande potencial paisagístico (Santos et al. 2009).

As populações dessa espécie que ocorrem no litoral dos estados de Alagoas, Bahia, Espírito Santo, Pernambuco e Rio de Janeiro foram descritas como J. brasiliensis (Ståhl 1992; Fabris et al. 1990), com base no menor número de óvulos e pelo caráter disjunto das mesmas (Mez 1903). Porém atualmente J. brasiliensis é tido como sinônimos heterotípico de $J$. armillaris (Ståhl 1992, Lista de Espécies da Flora do Brasil 2014).

A ocorrência em ambientes sujeitos a um intenso processo de fragmentação, devido ao crescimento industrial e urbano das zonas costeiras, levou à inclusão do seu sinônimo heterotípico, $J$. brasiliensis, na Lista Oficial de Espécies da Flora Brasileira Ameaçada de Extinção, na categoria "vulnerável" (Instrução Normativa No. 06, de 23 de setembro de 2008 - Ministério do Meio Ambiente 2008), apesar de, na época, Ståhl (1992) já tratar essas congêneres como sinônimo. $\mathrm{O}$ mesmo foi feito no estado do Espírito Santo, na ocasião da publicação da lista estadual de espécies ameaçadas (Simonelli \& Fraga 2007).

O processo de fragmentação promovido pela instalação de empreendimentos costeiros e o crescimento de áreas urbanas nas regiões litorâneas pode promover o isolamento de populações de $J$. armillaris, porém as faixas costeiras ocupadas pelas populações dessa espécie são normalmente sujeitas a intensos processos de erosão marinha e, consequentemente, fragmentação (Silva 2008), o que sugere que a mesma apresente estratégias de reprodução e sobrevivência relacionadas a ocupação dessas regiões. Dados sobre a biologia reprodutiva de $J$. armillaris seriam fundamentais para identificar estas estratégias de manutenção e sobrevivência, porém para esta espécie são conhecidos apenas os dados sobre o reduzido número de óvulos das populações descritas como J. brasiliensis (Mez, 1903) e dados sobre a fisiologia da germinação da mesma (Garcia \& Lucas 1994; Garcia 1999).

O presente estudo visa avaliar aspectos da polinização e produção de frutos de uma população de $J$. armillaris, descrita como J. brasiliensis por Garcia \& Lucas (1994), no Parque Estadual Paulo César Vinha (Guarapari, ES), descrevendo eventos relacionados à floração da população estudada, morfologia das flores, receptividade estigmática, além de dados do sistema de reprodução, viabilidade polínica e comportamento dos visitantes florais dessa espécie.

\section{Material e Métodos}

Área de estudo e caracterização da espécie

O trabalho foi realizado no Parque Estadual Paulo César Vinha (PEPCV) localizado no litoral sul do Espírito Santo, no município de Guarapari. A restinga do PEPCV compreende uma área continental de 1.480 ha, entre as coordenadas $20^{\circ} 33^{\prime}, 20^{\circ} 38^{\prime} \mathrm{S}$ e $40^{\circ} 23^{\prime}, 40^{\circ} 26^{\prime} \mathrm{W}$, apresentando um mosaico de formações vegetais típicas de áreas de restinga como formações herbáceas de beira de praia, formações arbustivas, formações florestais em depressões e sobre cordões arenosos e ainda a vegetação das margens das lagoas (Martins et al. 1999; Pereira 1990).

A população estudada integra a vegetação póspraia localizada na vertente continental do primeiro cordão costeiro, que é caracterizada por arbustos e sub-arbustos resistentes a forte influência do spray salino (Barbour et al. 1985; Pereira 1990; Fabris \& Pereira 1998). Nessa vegetação, J. armillaris apresenta porte arbustivo, de aproximadamente 1,5 $\mathrm{m}$, e copa regular e arredondada, formando moitas densas que se destacam na vegetação (Pereira 1990; Santos et al. 2009).

\section{Biologia reprodutiva}

O estudo foi realizado no período de setembro de 2004 até agosto de 2005, em uma população de aproximadamente 20 plantas de $J$. armillaris do PEPCV. Ao todo foram acompanhados 10 indivíduos que floresceram durante o período de estudo. Os dados relativos ao hábito das flores, características florais e eventos da biologia da flor, que ocorrem sucessivamente desde a antese até a deiscência, foram obtidos em incursões semanais por meio do acompanhamento de 80 flores, distribuídas irregularmente nos 10 indivíduos acompanhados. Durante o período de frutificação as incursões passaram a ser quinzenais para registro de dados referentes à presença de frutos verdes e de maduros, além do aparecimento de novas flores.

O tamanho da flor e de peças florais, como corola e cálice, foram medidos em 12 flores de seis plantas diferentes, para melhor descrição da flor e da interação com os polinizadores. Estas flores também foram avaliadas quanto à presença de osmóforos e nectários florais por meio de uma solução de vermelho neutro (Vogel 1990). A receptividade do estigma foi testada por meio de peróxido de hidrogênio 10 volumes (Zeisler 1938) em flores que foram mantidas ensacadas 
desde a fase de botão. Ao todo foram avaliadas 40 flores em dois estádios, relacionados à posição das peças florais, sendo 20 flores antes da exposição do estigma pelo afastamento dos estaminódios e estames e 20 flores depois da exposição do estigma. A receptividade também foi testada em 30 botões, 10 em cada fase de maturação, sendo estes: botões de $0,4 \mathrm{~cm}, 0,6 \mathrm{~cm}$ e $0,8 \mathrm{~cm}$ de comprimento. $\mathrm{O}$ número de óvulos por flor foi contado diretamente em 15 flores por meio de lupa estereoscópica, com aumento de até 80x. Exsicatas da população estudada foram depositadas no herbário da Universidade Federal do Espírito Santo (VIES 14.001, 14.002, 14.003 e 14.004).

A ocorrência de reprodução por crescimento vegetativo foi verificada por meio de escavações ao redor das raízes de 15 indivíduos de $J$. armillaris. As escavações visavam encontrar ligações por meio de raízes, na profundidade de até $50 \mathrm{~cm}$, ligando em linha reta plantas numa distância máxima de dois metros. Após verificado o isolamento do espécime foram realizados testes de polinização cruzada entre pares de plantas distintas.

Foram realizados tratamentos em 86 flores de 10 indivíduos considerados isolados, seguindo a metodologia de Goldenberg \& Shepherd (1998). Os tratamentos foram realizados em flores previamente ensacadas com sacos de tecido do tipo organza e, após os tratamentos, novamente ensacados até a queda da flor ou até a formação do fruto. Os tratamento foram de cinco tipos diferentes: 1. Controle: 26 flores disponíveis aos visitantes foram etiquetadas e acompanhadas para a verificação da formação de frutos e contagem de sementes, sendo 15 flores em cinco indivíduos ( 3 botões por planta) e 11 flores em uma amostra maior, que incluiu mais 5 indivíduos; 2. Autopolinização manual: 15 botões florais em 5 indivíduos ( 3 botões por planta) foram mantidos ensacados e polinizados manualmente com pólen da própria flor após à deiscência das anteras e afastamento dos estaminódios e estames; 3. Autopolinização espontânea: 15 botões em 5 indivíduos ( 3 botões por planta) permaneceram isolados nos sacos de organza até a queda da flor ou até a formação do fruto; 4. Polinização cruzada: 15 botões ensacados em 5 indivíduos (3 tratamentos por planta) foram emasculados durante a apresentação da fase masculina e polinizados manualmente com pólen de plantas distintas, após a deiscência das anteras; 5. Apomixia: 15 botões ensacados em 5 indivíduos (3 tratamentos por planta) foram emasculados e novamente isolados no saco de tecido até a abscisão ou formação do fruto. Percebida a formação do fruto os mesmos foram acompanhados por um período de 3 meses e posteriormente foram colhidos e dissecados para a verificação da taxa de formação de sementes.

A taxa de produção de sementes em frutos foi calculada por meio da dissecação de frutos oriundos de Polinização natural e de frutos maduros e sem sinal de predação coletados ao acaso no mês de maio de 2005. Frutos coletados que não apresentaram sementes foram incluídos na avaliação por estes corrigirem os valores das médias de produção considerando portanto o investimento em frutos no montante de flores acompanhadas. Os frutos resultantes dos tratamentos também foram dissecados para a contagem do número de sementes, visando comparar essa produção com o obtido em frutos não manipulados.

Para verificar se a porcentagem de frutos produzidos nos diferentes tratamentos foi significativamente diferente, os valores percentuais foram comparados por meio do teste não paramétrico para medidas repetidas de Friedman, comparando os tratamentos distribuídos equitativamente sobre o conjunto de 5 plantas. A presença de auto-incompatibilidade foi verificada por meio do Índice de Bullock (1985) cuja fórmula é: ISI $=\%$ de frutos de autofecundação $/ \%$ de frutos de cruzamento. Segundo Bullock (1985) o valor de 0,25 seria o limite máximo obtido pelo índice para definir a planta como auto-incompatível.

Para determinar a quantidade e viabilidade de grãos de pólen, foram coletados em cinco plantas diferentes um botão no início da antese, quando as pétalas começaram a abrir, uma flor na fase inicial da antese, quando as pétalas já estavam afastadas (48 horas após a antese), e uma flor com os estigmas expostos (72 horas após a antese), totalizando 15 flores coletadas, 5 em cada fase e em cada planta. Todas as anteras da flor coletada foram maceradas e diluída em volume fixo de solução de carmim acético. O diluído foi colocado em câmara de Neubauer para contagem dos grãos de pólen viáveis e inviáveis (Dafni 1992). Os valores percentuais de viabilidade de pólen de cada flor foram considerados réplicas na comparação da viabilidade polínica das diferentes fases. Os valores percentuais de viabilidade de pólen das flores de diferentes fases também foram comparados pela análise de variância de Friedman. A razão entre o número médio de grãos de pólen por flor pelo número médio de óvulos por flor foi utilizada como inferência sobre o sistema de cruzamento, conforme Cruden (1977). 
As observações de visitantes foram feitas durante dias do mês de dezembro de 2004 e janeiro de 2005, quando as plantas acompanhadas para o estudo dos polinizadores apresentavam maior número de flores em relação ao número de botões. As observações foram realizadas em dias ensolarados e sem a previsão de chuvas. $\mathrm{O}$ comportamento dos visitantes florais foi registrado diretamente em flores focais escolhidas para serem acompanhadas no turno da manhã, entre $8 \mathrm{~h} \mathrm{e} 12 \mathrm{~h}$, ou no turno da tarde, entre $13 \mathrm{~h} \mathrm{e} 18 \mathrm{~h} 30 \mathrm{~min}$. As flores focais ficaram sobre observação durante todo o turno, porém eram acompanhadas em intervalos de $20 \mathrm{~min}$, com descanso de $10 \mathrm{~min}$ entre cada observação, quando eram produzidas imagens dos visitantes. Ao final do turno de observação os visitantes foram coletados para identificação. Também foi realizada uma observação noturna das $19 \mathrm{~h}$ até $23 \mathrm{~h}$. Ao todo foram realizadas $1.680 \mathrm{~min}$ de observação, 640 min em 4 turnos da manhã; $880 \mathrm{~min}$ em 4 turnos da tarde e $160 \mathrm{~min}$ na noite. As observações foram feitas em 16 flores de ramos distintos de 5 diferentes plantas. Os visitantes coletados foram identificados pelo Centro de Estudos Faunísticos e Ambientais (CDZOO) do Departamento de Zoologia da Universidade Federal do Paraná ( $n^{\circ}$ de referência 1719/05) e depositados na coleção entomológica do Centro Universitário Vila Velha (UVV).

\section{Resultados}

Na população estudada algumas plantas já apresentavam frutos no início do período de estudo, setembro de 2004, porém os primeiros botões foram registrados com a chegada da estação chuvosa, em meados de outubro, e o período de floração teve início em novembro de 2004. Durante o mês de dezembro e janeiro as plantas consideradas continuaram floridas e a partir de fevereiro de 2005 começaram a apresentar somente frutos. No início de março apenas uma planta continuava com flores. Os frutos desta floração ficaram maduros no período de janeiro a maio de 2005 , fim da estação chuvosa. Também foi observada a presença de frutos em um dos indivíduos avaliados até o final de agosto e setembro de 2005 (Fig. 1).

As inflorescências estão dispostas em racemos com até cinco flores axilares. Os botões são brancos esverdeados e se desenvolvem até alcançarem uma coloração albo-amareladas, com um tamanho médio ( \pm desvio padrão) de 7,5 $( \pm$ $0,6) \mathrm{mm}$. A corola é pentâmera e actinomorfa, composta por pétalas com média de tamanho de $6,4( \pm 0,7) \mathrm{mm}(\mathrm{n}=12)$, fusionadas em $2 / 3$ do seu comprimento formando uma câmara. $\mathrm{O}$ cálice também é pentâmero, verde e gamosépalo com tamanho médio de 2,3 $( \pm 0,3) \mathrm{mm}(\mathrm{n}=12)$. As flores são hermafroditas com o androceu constituído de cinco estames opostos aos lobos da corola e cinco estaminódios alternos a estes, soldados ao tubo da corola (Fig. 2). As anteras são ditecas, com deiscência longitudinal, dorsifixa e extrorsa. $\mathrm{O}$ gineceu possui ovário súpero, estilete terminal, curto, estigma globoso terminal. A superfície estigmática é branco-amarelada se tornando escurecida, com tons marrons, a partir da antese.

As flores de $J$. armillaris apresentaram odor adocicado durante todo o período de exposição. Foi verificada a presença de osmóforos nos estaminódios e nas pétalas. Não foi constatada a presença de nectários florais. O ovário é unilocular, com placentação axial livre, pluriovular (cinco carpelos) e um número médio de $25( \pm 5)$ óvulos $(\mathrm{n}=12)$. O endocarpo é duro nos frutos imaturos e gelatinoso nos maduros.

As flores apresentaram uma sequência de estágios com períodos bem definidos para a apresentação da parte masculina, no início da antese, seguida pela apresentação das estruturas femininas (Tab. 1, Fig. 3). A abertura das pétalas durou aproximadamente 24 horas, iniciando-se

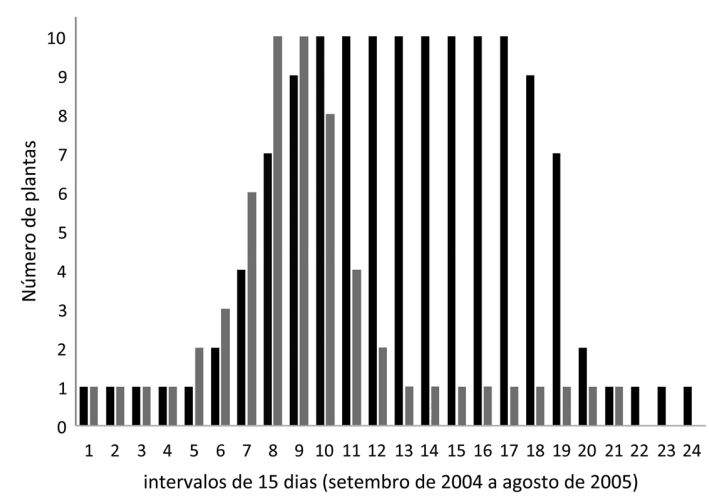

Figura 1 - Número de plantas de Jacquinia armillaris Jacq. (Primulaceae) que apresentaram flores (barras cinzas) e frutos (barras pretas) ao longo do período de estudo, de setembro de 2004 a agosto de 2005, na população do Parque Estadual Paulo Cesar Vinha, Guarapari, ES.

Figure 1 - Plants of Jacquinia armillaris Jacq. (Primulaceae) that are showing flowers (gray bars) and fruits (black bars) during the study period, between September 2004 and August 2005, at one population of Parque Estadual Paulo Cesar Vinha, Guarapari, ES. 
Tabela 1 - Cronologia de eventos de flores de Jacquinia armillaris Jacq. (Primulaceae) no Parque Estadual Paulo César Vinha, Guarapari, ES.

Table 1 - Chronology of flower events of Jacquinia armillaris Jacq. (Primulaceae) in Parque Estadual Paulo Cesar Vinha, Guarapari, ES.

\begin{tabular}{|c|c|c|c|c|c|c|c|}
\hline Eventos & Dia 1 & Dia 2 & Dia 3 & Dia 4 & Dia 5 & Dia 6 & Dia 7 \\
\hline \multicolumn{8}{|l|}{ Odor } \\
\hline \multicolumn{8}{|l|}{ Abertura das pétalas } \\
\hline \multicolumn{8}{|c|}{ Afastamento dos estaminódios } \\
\hline \multicolumn{8}{|l|}{ Afastamento das anteras } \\
\hline \multicolumn{8}{|l|}{ Receptividade do estigma } \\
\hline Abscisão das peças florais & & & & & & & \\
\hline
\end{tabular}

sempre no início da noite, a partir das 18 horas. Aproximadamente 48 horas após a abertura das pétalas ocorria o afastamento completo dos estaminódios, seguido pelos estames, o que resultava na exposição do estigma. Segundo o teste com peróxido de oxigênio, os estigmas já se encontravam receptivos pré-antese e antes do afastamento dos estames e apresentação da parte feminina. As anteras também se apresentaram deiscentes em botões pré-antese. O tempo de duração da flor de $J$. armillaris é de cinco a seis dias. Na senescência da flor, todo o conjunto de pétalas, estaminódios e estames caem.

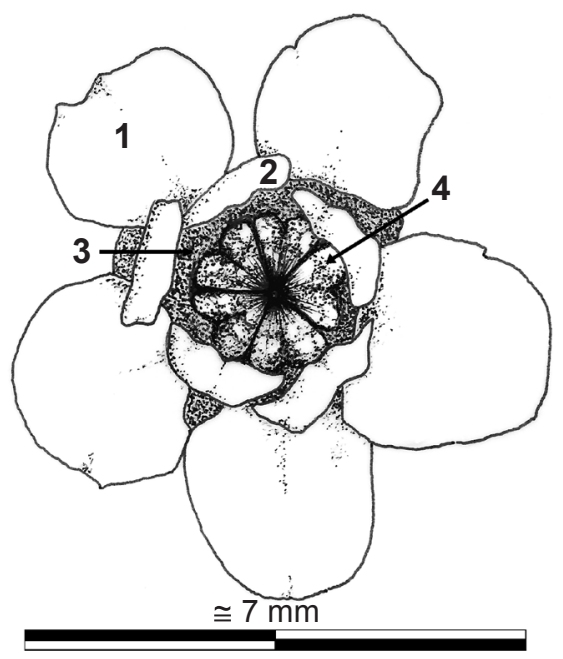

Figura 2 -Flor de Jacquinia armillaris Jacq. (Primulaceae) com a apresentação das pétalas (1); estaminódios (2); câmara floral (3); anteras no interior da corola da flor (4). Figure 2 - Flower of Jacquinia armillaris Jacq. (Primulaceae) exposing petals (1); staminodes (2); floral chamber (3); the anthers in the middle of flower (4).
A taxa de produção de frutos no Controle foi de aproximadamente $45 \%$, enquanto a taxa de sucesso nos tratamentos de Autopolinização manual foi de aproximadamente $25 \%$ e, a taxa de sucesso obtido na Polinização cruzada foi de aproximadamente $15 \%$ (Tab. 2). As escavações não evidenciaram qualquer ligação entre indivíduos próximos, de forma que os tratamentos com pólen de indivíduos distantes por mais de dois metros nos tratamentos de Polinização cruzada podem ser considerados cruzamentos efetivos. Os tratamentos de Autopolinização espontânea e Apomixia não apresentaram resultados positivos. As flores que
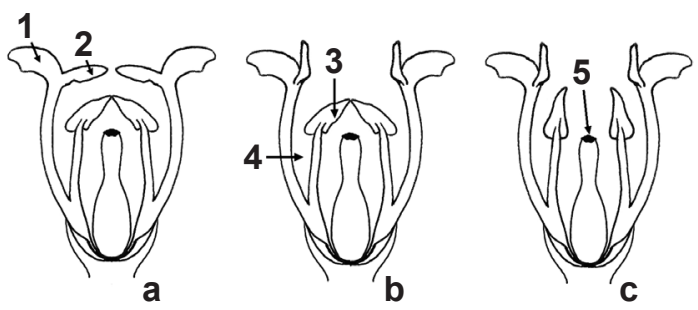

Figura 3 - Esquemas da cronologia de eventos da flor de Jacquinia armillaris Jacq. (Primulaceae) - a. início da antese, com as pétalas (1) abertas e os estaminódios (2) protegendo o androceu e gineceu; b. no primeiro dia de abertura com a apresentação dos estames, expondo estames e anteras (3) no interior da câmara floral (4); e c. no terceiro dia de abertura com a apresentação do gineceu e da superficie estigmática (5), após o afastamento dos estames. Figure 3 - Scheme of flower events of Jacquinia armillaris Jacq. (Primulaceae) - a. flower in the beginning of the anthesis, petals (1) stay open but staminodes (2) cover androecium and gynoecium; $b$. flower at first day, exposing stamens and anthers (3) in the middle of floral chamber (4); and c. flower at the third day exposing the gynoecium and the stigma surface (5) among the stamens. 
Tabela 2 - Tratamentos realizados para testar o sistema reprodutivo de Jacquinia armillaris Jacq. (Primulaceae), mostrando o número de flores utilizadas, frutos obtidos e o sucesso (\%) alcançado na formação de frutos.

Table 2 - Treatments performed to test the reproductive system Jacquinia armillaris Jacq. (Primulaceae), showing the number of flowers used, fruits obtained and success $(\%)$ reached in fruit formation.

\begin{tabular}{lccc}
\hline Tratamentos & Flores $\left(\mathbf{n}^{\mathbf{0}}\right)$ & Frutos $\left(\mathbf{n}^{\mathbf{0}}\right)$ & Sucesso (\%)* \\
\hline Polinização cruzada & 15 & 2 & 13,33 \\
Autopolinização manual & 15 & 4 & 26,66 \\
Autopolinização espontânea & 15 & 0 & - \\
Apomixia & 15 & 0 & - \\
Polinização natural (controle) & 26 & 12 & 46,15 \\
\hline
\end{tabular}

* Não foram encontradas diferenças significativas $(\mathrm{p}<0,05)$ segundo o teste de Friedman para medidas repetidas.

receberam pólen nos tratamentos foram abortadas em diferentes fases do desenvolvimento, até um período máximo de 16 semanas, já em fase adiantada de crescimento. Na comparação da percentagem de frutos produzidos nos tratamentos com resultados positivos não foi verificado diferenças significativas $\left(\chi^{2}=5,60 ; \mathrm{N}=4 ; \mathrm{gl}=2 ; p=\right.$ $0,06)$. O valor do índice de auto-incompatibilidade (ISI) foi de 2,0.

$\mathrm{O}$ número médio de sementes em frutos foi $2,4( \pm 1,5)$, considerando os 12 frutos resultantes do tratamento de Polinização natural e 19 frutos coletados aleatoriamente. Seis frutos maduros coletados aleatoriamente não apresentaram sementes. Com relação aos tratamentos controlados de Polinização cruzada e Autopolinização manual, o número médio de sementes por fruto foi 2,7 $( \pm$ $0,6, \mathrm{n}=11)$. O número de sementes encontradas nos frutos não manipulados representou 9,6 \% do número médio de óvulos, enquanto o número de sementes encontrado nos tratamentos foi de $10,8 \%$.

$\mathrm{O}$ número médio de grãos de pólen por flor foi de $2647( \pm 474,19 ; n=15)$ e o número médio de pólens viáveis, independentemente do tempo decorrido desde à abertura da flor, foi de 1361 ( \pm $390,27 ; n=15)$ (Tab. 3). A variação na porcentagem de grãos de pólen viáveis das diferentes fases (botão no início da antese, flores de $48 \mathrm{~h}$ e flores de $72 \mathrm{~h}$ ) não foi estatisticamente significativa $\left(\chi^{2}\right.$ $=2,80 ; \mathrm{N}=5 ; \mathrm{gl}=2 ; p=0,24)$, indicando que a viabilidade polínica não varia ao longo do tempo de exposição da flor. A razão entre o número médio de grãos de pólen viáveis por flor pelo número médio de óvulos foi de 54,04 grãos/óvulo, de forma que a espécie pode ser considerada autogâmica facultativa, conforme classificação de Cruden

Tabela 3 - Valores médios de viabilidade polínica de flores de uma população de Jacquinia armillaris Jacq. (Primulaceae) considerando diferentes fases do desenvolvimento da flor.

Table 3 - Mean values of pollen viability of Jacquinia armillaris Jacq. (Primulaceae) flowers, considering distinct flower phases.

\begin{tabular}{lcccc}
\hline Tratamentos & $\begin{array}{c}\text { Flores } \\
\left(\mathbf{n}^{\mathbf{0}}\right)\end{array}$ & Grãos de pólen & Pólen viável & Percentual de grãos viáveis* \\
\cline { 3 - 5 } & 5 & $2626( \pm 27,88)$ & $1370( \pm 92,36)$ & $52,17( \pm 2,97)$ \\
Primeiras $24 \mathrm{~h}$ & 5 & $2854( \pm 44,24)$ & $1361( \pm 192,94)$ & $47,70( \pm 6,03)$ \\
Flores de $48 \mathrm{~h}$ & 5 & $1801( \pm 729,71)$ & $1036( \pm 674,13)$ & $57,52( \pm 9,58)$ \\
\hline Flores de $72 \mathrm{~h}$ & 5 & $2647( \pm 474,19)$ & $1361( \pm 390,27)$ & $52,50( \pm 7,70)$ \\
\hline Média total & 15 &
\end{tabular}

* Não foi encontrada diferenças significativas $(\mathrm{p}<0,05)$ segundo o teste de Friedman para medidas repetidas. 
(1977). Considerando o número total de grãos de pólen, conforme classificação de Cruden (1977), a razão pólen/óvulo encontrada foi de 105,04 grãos/ óvulo.

No total foram registradas 50 visitas, sendo 23 de Carpophilus sp. (Nitidulidae, Coleoptera), 18 de Horistonotus sp. (Elateridae, Coleoptera), quatro de Formicidae, quatro de Orthoptera e uma de Curculionidae. As visitas ocorreram tanto no período noturno quanto no período diurno. Os Coleoptera observados frequentaram flores com o gineceu coberto e com o gineceu exposto e se alimentaram de grãos de pólen diretamente nas anteras. Nas flores com o gineceu exposto os Coleoptera caminhavam sobre os estigmas enquanto se alimentavam de pólen. Em todas as visitas de Coleoptera foi registrado a presença de pólen depositado no corpo dos visitantes. As visitações dos Coleoptera duraram um tempo superior aos intervalos de observação podendo, em alguns casos abranger período superior a quatro intervalos de observação (aproximadamente duas horas). Formicidae, Curculionidae e Orthoptera caminhavam sobre as flores porém não entraram em contato com o pólen nas anteras ou com partes reprodutivas femininas.

\section{Discussão}

A floração, frutificação e liberação de sementes de Jacquinia armillaris no período chuvoso, coincide com o padrão observado em diversas plantas não anemocóricas da restinga (Suizane et al. 2012; Zamith \& Scarano 2004). A produção de flores e liberação de sementes da espécie também coincide com uma maior taxa de floração e frutificação de outras espécies resistentes a salinidades da formação halófila e psamófila reptante da área do PEPCV, estudada por Pereira et al. (1992). A persistência de plantas produzindo flores e frutos durante um período maior do que o pico de floração, também segue o padrão geral das plantas da restinga, que tendem a apresentar uma grande heterogeneidade na época e na duração da dispersão das sementes das espécies (Suizane et al. 2012; Zamith \& Scarano 2004). Para alguns autores essas seriam estratégias para as circunstâncias de grande imprevisibilidade ambiental das restingas (Scarano 2002), o que tende a produzir certa abundância de recursos durante todo o ano e garantir a presença de polinizadores e dispersores (Almeida et al. 2004).

A estrutura das flores de $J$. armillaris formando uma pequena câmara para abrigar polinizadores, acompanha padrões observados em 54 espécies de plantas, de 18 diferentes famílias, polinizadas por besouros (Bernhardt 2000). Outras características relacionadas à síndrome de polinização por besouros (Faegri \& Van Der Pijl 1980) também foram registradas em J. armillaris como: ovário súpero (Grant 1950); flores esbranquiçadas, presença de odor (Smith \& Meeuse 1966) e a exposição em tempos diferentes de estruturas com diferentes funções sexuais na flor, conhecida como dicogamia (Bawa \& Beach 1981).

A dicogamia verificada em $J$. armillaris, difere do encontrado na bibliografia sobre a origem da dicogamia em plantas, que associa a polinização por besouros com a protoginia (Sargent $\&$ Otto 2004). A protoginia seria comum em cantarofilia pois evitaria a autopolinização causada pelo limitado deslocamento dos besouros e pelo tempo de residência dos besouros nas câmaras. Porém a evolução e ocorrência de protandria em espécies cantarófilas tem sido relacionada a casos específicos, relacionados à disposição e tempo das flores de diferentes sexos nas inflorescências e ao comportamento dos visitantes (Routley \& Husband 2003), sendo comum a ocorrência desse tipo de dicogamia em flores que recebem pequenos insetos polinívoros que demoram um maior tempo na inflorescência e em espécies que apresentam somente flores femininas por um longo período, quando o pólen já foi praticamente removido das anteras (McKone et al. 1995). Esse seria o caso de $J$. armillaris, que são: visitadas por besouros tipicamente polinívoros (Tenhet \& Howe 1939; Kirk-Spriggs 1996); apresentam flores dispostas em pequenas inflorescências; demoram mais de um dia para apresentar as peças florais femininas e ficam expostas por um longo período. Essas características garantem que as visitas durante a fase feminina ocorram após a retirada de grande parte do recurso pólen, o que pode aumentar as taxas de cruzamento, porém em valores inferiores à obtida em espécies protogínicas (McKone et al. 1995).

A taxa de formação de frutos nos eventos de polinização natural $(46 \%)$ pode ser considerada baixa se comparado aos $72,5 \%( \pm 12,5)$ encontrado por Sutherland \& Delph (1984), como valor médio para 129 plantas autocompatíveis. Faria et al. (2006) descreve a polinização nos ambientes de restinga como limitada por rigores intrínsecos desse ecossistema, o que gera irregularidades na taxa de produção (Scarano 2002; Scarano et al. 2005; Faria et al. 2006). No caso de J. armillaris, 
cujas populações são polinizadas por besouros, que promovem limitado fluxo gênico (Young 1986), os eventos de baixa produção de frutos podem se tornar mais comuns caso o quadro de fragmentação amplie a distância entre remanescentes cada vez menores (Fahrig 2003; Hobbs \& Yates 2003).

Em $J$. armillaris os valores obtidos pelo índice de auto-incompatibilidade (superior ao limite de 0,25 definido por Bullock 1985), a formação de frutos nos tratamentos de polinização cruzada e a não produção de frutos em eventos de polinização espontânea sugere que a população de $J$. armillaris estudada é autocompatível e que depende da polinização promovida pelos visitantes florais. Diversos autores têm relacionado a ocorrência de autocompatibilidade aos ambientes onde a polinização é incerta (Motten 1986; Silvertow \& Doust 1993; Nason et al. 1996; James et al. 1998). Na restinga, como uma faixa territorial de origem geológica recente, seria esperado que espécies autocompatíveis tivessem maior sucesso na colonização destes ambientes ainda carentes de polinizadores, conforme lei de Baker (Baker 1955; Cheptou 2012). No caso de J. armillaris a autopolinização seria uma vantagem para a colonização das faixas mais litorâneas e mais recentes e também aos seus polinizadores que tendem a promover uma limitada dispersão de pólen, realizando autocruzamentos (Motten 1986; Silvertow \& Doust 1993; Nason et al. 1996; James et al. 1998).

Apesar da razão pólen viável/óvulo ser um índice que apresenta grande variação entre espécies e populações, os valores encontrados para a população estudada foram inferiores ao registrado em por Cruden (1977) em 20 espécies com autogamia facultativa distribuídas em 11 Famílias e 7 Ordens diferentes, que apresentaram valores médios de polén/óvulo de 162,5 ( $\pm 22,1$ ) (ver também Cruden, 2000; Jürgens et al. 2002). Essa pequena viabilidade polínica precisa ser avaliada juntamente com a questão do pequeno número de óvulos, descrita por Mez (1903) para populações por ele consideradas como J. brasiliensis, isso porque mutações ou rearranjos que afetam a taxa de formação de gametas viáveis e, consequentemente, o sucesso reprodutivo individual têm, naturalmente, grande dificuldade de se estabelecerem e/ou fixarem em populações que se reproduzem sexuadamente, ocorrendo somente em pequenas populações com altas taxas de cruzamento parental e estando relacionados a eventos especiação (Rieseberg 2001; Husband 2004).
Por fim, a baixa taxa de produção observada em $J$. armillaris pode ser resultado de um ano com baixas taxas de visitação e/ou polinizações e fertilizações, conforme descrito para outras espécies de restinga (Faria et al. 2006). Em $J$. armillaris a pequena taxa de produção ainda precisa ser considerada no contexto de baixos níveis de produção e disponibilidade de pólen no sistema além do fato da espécie ser polinizada por besouros. Ainda é importante considerar que $J$. armillaris está associada a faixas costeiras sujeitas a processos naturais de fragmentação pela erosão costeira (Dennison 2008; Silva 2008). Evidentemente que essas características podem ter sido assimiladas pela evolução de características distintas nas diferentes populações, como a autocompatibilidade, que pode ser um caráter importante se considerado a baixa razão pólen viável/óvulo (Cruden 2000; Zhao \& Sun 2009). Diante de um quadro de fragmentação de habitat pela ação antrópica verifica-se ainda a necessidade de estudos genéticos de $J$. armillaris, visando dimensionar a variabilidade que ainda resta na espécie, e ainda, subsidiar decisões taxonômicas relacionadas ao grupo, diminuindo dúvidas sobre a taxonomia e origem de $J$. armillaris.

\section{Agradecimentos}

A Nicolay Cunha, as correções e orientação na realização dos testes estatísticos, e a Ana Cristina Petry, a ajuda na realização das análises. A Diego Queiroz Sanz, Carolina Yamamoto Santos Martins, Filipe Andrich e Frederico Jacob Eutrópio, o auxílio nos trabalhos de campo. A Herbert Costa Moraes, João Damasceno Lopes Martins e Paulo Roberto, o auxílio em laboratório. A Marcelo Passamani e à Isabela Galarda Varassin, as orientações quanto à bibliografia. A Hélio Sá Santos, a identificação de parte dos insetos. Ao Centro de Estudos Faunísticos e Ambientais, a identificação dos besouros.

\section{Referências}

Almeida, E.M.; Storni, A.; Ritter, P.D. \& Alves, M.A.S. 2004. Floral visitors of Tillandsia stricta Sol. (Bromeliaceae) at Restinga of Jurubatiba, Macaé, Rio de Janeiro, Brazil. Vidalia 2: 30-35.

Angiosperm Phylogeny Group. 2009. An update of the Angiosperm Phylogeny Group classification for the orders and families of flowering plants. APG III. Botanical Journal of the Linnean Society 161: 105-121

Baker, H.G. 1955. Self-compatibility and establishment after 'long distance' dispersal. Evolution 9: 347-348. 
Barbour, M.G.; DeJong, T.M. \& Pavlik, B.M. 1985. Marine beach and dune plant communities. In: Chabot, B.F. \& Mooney, H.A. (eds.). Physiological Ecology of North American Plant Communities. Chapman and Hall, New York. Pp. 294-322.

Bawa, K.S. \& Beach B.H. 1981. Evolution of sexual systems in flowering plants. Annals of the Missouri Botanical Garden 68: 254-274.

Bernhardt, P. 2000. Convergent evolution and adaptive radiation of beetle-pollinated angiosperms. Plant Systematics and Evolution 222: 293-320.

Bullock, S.H. 1985. Breeding systems in the flora of a tropical deciduous forest. Biotropica 17: 287-301.

Cheptou, P.-O. 2012. Clarifying Baker's Law. Annals of Botany 109: 633-641.

Cruden, R.W. 1977. Pollen-ovule ration: a conservative indicator of breading systems in flowering plants. Evolution 31: 32-46.

Cruden, R.W. 2000. Pollen grains: why so many? Plant Systematics and Evolution 222:143-165.

Dafni, A. 1992. Pollination ecology: a practical approach. Oxford University Press, Oxford. 250p.

Dennison W.M. 2008. Environmental problem solving in coastal ecosystems: a paradigm shift to sustainability. Coastal and Shelf Science 77: 185-196.

Fabris, L.C. \& Pereira, O.J. 1998. Florística da formação pós-praia, na restinga do Parque Estadual Paulo César Vinha, Guarapari (ES). In: Anais do IV Simpósio de Ecossistemas Brasileiros. Vol. 3. Academia de Ciências do Estado de São Paulo, São Paulo. Pp. 117-128.

Fabris, L.C.; Pereira, O.J. \& Araújo, D.S.D. 1990. Análise fitossociológica na formação pós-praia da Restinga de Setiba - Guarapari - ES. In: Anais do II Simpósio de ecossistemas da Costa Sul e Sudeste brasileira: estrutura, função e manejo. Vol. 1. Academia de Ciências do Estado de São Paulo, São Paulo. Pp.455-466.

Faegri, K. \& van der Pijl, L. 1980. The principles of pollination ecology. $3^{\text {rd }}$ ed. Pergamon Press, New York. 291p.

Fahrig, L. 2003. Effects of habitat fragmentation on biodiversity. Annual Review of Ecology and Systematics 34: 1-26.

Faria, A.P.G.; Matallana, G.; Wendt, T. \& Scarano, F.R. 2006. Low fruit set in the abundant dioecious tree Clusia hilariana (Clusiaceaea) in a Brazilian restinga. Flora 201: 606-611.

Garcia, Q.S. \& Lucas, N.M.C. 1994. Germinative behaviour of Jacquinia brasiliensis seeds. Revista Brasileira de Botânica 17: 13-18.

Garcia, Q.S. 1999. Germination ecology of Jacquinia brasiliensis, an endemic species of the Brazilian "Restinga", in relation to salinity. Tropical Ecology 40: 207-212.
Goldenberg, R. \& Shepherd, G.J. 1998. Studies on the reproductive biology of Melastomataceae in cerrado vegetation. Plant Systematics and Evolution 211: 13-29.

Grant, V. 1950. Protection of ovules in flowering plants. Evolution 4: 179-201.

Hobbs, R.J. \& Yates, C.J. 2003. Impacts of ecosystem fragmentation on plant populations: generalizing the idiosyncratic. Australian Journal of Botany 51: 471-488.

Husband, B.C. 2004. Chromosomal variation in plant evolution. American Journal of Botany 91: 621-625.

Jürgens, A.;'Witt, T. \& Gottsberger, G. 2002. Pollen grain numbers, ovule numbers and pollen-ovule ratios in Caryophylloideae: correlation with breeding system, pollination, life form, style number, and sexual system. Sexual Plant Reproduction 14: 279-289.

Källersjö, M.; Bergqvist, G. \& Anderberg, A.A. 2000. Generic realignment in primuloid families of the Ericales s. 1.: a phylogenetic analysis based on DNA sequences from three chloroplast genes and morphology. American Journal of Botany 87: 1325-1341.

Kirk-Spriggs, A.H. 1996. Pollen beetles Coleoptera: Kateretidae and Nitidulidae: Meligethinae. Handbooks for the Identification of British Insects. Vol. 5(6a). Royal Entomological Society of London, London. $157 \mathrm{p}$.

Leite, C.O. 1990. Biologia da reprodução de Allagoptera arenaria (Gomes) O. kuntze (Diplothemium maritimum Mart.) - Palmae. Dissertação de Mestrado. Universidade Federal do Rio de Janeiro, Rio de Janeiro. 80p.

Lista de Espécies da Flora do Brasil 2014. Disponível em <http://floradobrasil.jbrj.gov.br/>. Acesso em 20 fevereiro 2014.

Martins, M.L.L.; Carvalho-Okano, R.M. \& Luceño, M. 1999. Cyperaceae do Parque Estadual Paulo César Vinha, Guarapari, ES, Brasil. Acta Botanica Brasílica 13: 187-222.

McKone, M.J.; Ostertag, R.; Rauscher, J.T.; Heiser, D.A. \& Russell, L. 1995. An exception to Darwin's syndrome: floral position, protogyny, and insect visitation in Besseya bullii (Scrophulariaceae). Oecologia 101: 68-74.

Mez, C. 1903. Theophrastaceae. In: Engler, A. (ed.). Das Pflanzenreich 15 (IV 236a). Verlag von Wilhelm Engelmann, Leipzig. Pp. 148.

Ministério do Meio Ambiente 2008. Lista Oficial de Espécies da Flora Brasileira ameaçadas de Extinção. Instrução Normativa №. 06 de 23 set 2008. Disponível em <http://portal.saude.gov.br/portal/arquivos/pdf/ MMA_IN_N_6.pdf $>$. Acesso em 25 abril 2013.

Motten, A.F. 1986. Pollination ecology of the spring wildflower community of a temperate deciduous forest. Ecological Monographs 56: 21-42. 
Nason, D.; Herre, E.A. \& Hamrick, J.L. 1996. Paternity analysis of the breeding structure of strangler fig populations: evidence for substantial long-distance wasp dispersal. Journal of Biogeography 23: 501512.

Pereira, O.J. 1990. Caracterização fitofisionômica da restinga de Setiba-Guarapari-Espírito Santo. Pp. 207-219. In: Anais do II Simpósio de ecossistemas da Costa Sul e Sudeste brasileira: estrutura, função e manejo. Vol. 3. Academia de Ciências do Estado de São Paulo, São Paulo. Pp. 207-219.

Pereira. O.J.; Thomaz. L.D. \& Araújo. D.S.D. 1992. Fitossociologia da vegetação de ante dunas da restinga de Setiba/Guarapari e em Interlagos/Vila Velha. ES. Boletim do Museu de Biologia Mello Leitão 1: 65-75.

Routley, M.B. \& Husband, B.C. 2003. The effect of protandry on siring success in Chamerion angustifolium (Onagraceae) with different inflorescence sizes. Evolution 57: 240-248.

Rieseberg, L.H. 2001. Chromosomal rearrangements and Speciation. Trends in Ecology and Evolution 16: 351-358.

Santos, M.G.; Fevereiro, P.C.A.; Reis, G.L. \& Barcelos, J.I. 2009. Recursos vegetais da Restinga de Carapebus, Rio de Janeiro, Brasil. Revista de Biologia Neotropical 6: 35-54.

Santos, M.G.; Fevereiro, P.C.A.; Reis; G.L.; Barcelos, J.I. \& Ney, F.M.M.A. 2009b. Plantas da Restinga, Potencial Econômico. Technical Books Editora, Rio de Janeiro. 139 p.

Sargent, R.D. \& Otto, S.P. 2004. A phylogenetic analysis of pollination mode and the evolution of dichogamy in angiosperms. Evolutionary Ecology Research 6: 1183-1199.

Scarano, F.R. 2002. Structure, function and floristic relationships of plant communities in stressful habitats marginal to the Brazilian Atlantic Rainforest. Annals of Botany 90: 517-524.

Scarano, F.R.; Duarte, H.M.; Franco, A.C.; Geßler, A.; de Mattos, E.A.; Nahm, M.; Rennenberg, H.; Zaluar, H.L.T. \& Lüttge, U. 2005. Ecophysiology of selected tree species in different plant communities at the periphery of the Atlantic Forest of SE-Brazil I. Performance of three different species of Clusia in an array of plant communities. Trees 19: 497-509.

Silva, C.R. 2008. Geodiversidade do Brasil: conhecer o passado, para entender o presente e prever o futuro. Serviço Geológico do Brasil CPRM, Rio de Janeiro. 264p.
Silvertow, J.W. \& Doust, J.L. 1993. Introduction to plant population biology. Blackwell Scientific Publication, Washington. 210p.

Smith, B.N. \& Meeuse, B.J.D. 1966. Production of volatile amines and skatole at anthesis in some arum lily species. Plant Physiology 41: 343-347.

Ståhl, B. 1992. On the identity of Jacquinia armillaris (Theophrastaceae) and related species. Brittonia 44: 54-60.

Ståhl, B. 2010. Theophrastaceae. Flora Neotropica Monograph. Vol. 105. The New York Botanical Garden Press, New York. 160p.

Suizani, C.V.; de Lima, H.A.; Rodarte, A.T.A. \& Benevides, C. 2012. Flowering phenology of a bromeliaceae community of an environmental protection area (EPA) in the restinga of Maricá (RJ, Brazil) as compared to other habitats of the southeastern Brazilian atlantic Rain forest. Brazilian Journal of Ecology 14: 88-95.

Sutherland, S. \& Delph, L.F. 1984. On the importance of male fitness in plants: patterns of fruit-set. Ecology 65: 1093-1104.

Tenhet, J.N. \& Howe, E.W. 1939. The sand wireworm and its control in the South Caroline Coastal plain. United States Department of Agriculture, Washington DC. 659p.

Vogel, S. 1990. The role of scent glands in pollination. Smithsonian Institution Libraries; National Science Foundation, Washington. 202p.

Weinberg, B. 1984. Componentes da vegetação remanescente do litoral de Vila Velha e norte de Guarapari - ES: usos em tratamentos paisagístico em cidades da orla marítima. In: Lacerda, L.D.; Araujo, D.S.D.; Cerqueira, R.; \& Turcq, B. Restinga: origem, estrutura, processos. CEUFF, Niterói. Pp. 227-232.

Young, H.J. 1986. Beetle pollination of Dieffenbachia longispatha (Araceae). American Journal of Botany 73: 931-944.

Zamith, L.R. \& Scarano, F.R. 2004. Produção de mudas de espécies das Restingas do município do Rio de Janeiro, RJ, Brasil. Acta Botanica Brasilica 18: 161-176.

Zhao, X. \& Sun, W. 2009. Abnormalities in sexual development and pollinator limitation in Michelia coriacea (Magnoliaceae), a critically endangered endemic to Southeast Yunnan, China. Flora 204: 463-470.

Zeisler, M. 1938. Uber die Abgrenzung der eigentlichen Narbenfläche mit Hilfe von Reaktionen. Beiheft zum Botanisches Zentralblatt 58: 308-318. 